\title{
Determination of Aflatoxin M1 in Pasteurized Liquid and Powdered Milk Products Imported to Iran
}

\author{
Masoumeh Mahmoodi Maymand ${ }^{* 1}(\mathbb{D})$, Mansooreh Mazaheri ${ }^{2}(\mathbb{D})$, Mahboobeh Talebi Mehrdar $^{3}(\mathbb{D}$ \\ 1. MSc of Toxicology, Standard Research Institute (SRI), Karaj, Iran. \\ 2. PhD of Biophysics, Standard Research Institute (SRI), Karaj, Iran. \\ 3. Department of Biochemistry, Payame Noor University, Tehran, Iran.
}

\begin{tabular}{ll}
\hline Article Info & A B S T R A C T \\
\hline $\begin{array}{l}\text { Article type: } \\
\text { Original Article }\end{array}$ & Background: \\
\hline Article History: & Mycotoxins are the secondary metabolites of molds and have adverse effects \\
Received: $2019-03-04$ & on humans, animals, and crops, resulting in illnesses and economic losses. \\
Accepted: $2019-04-17$ & Aflatoxin M1 (AFM1) is a hepatocarcinogen found in the milk from animals \\
& that have consumed feeds contaminated with aflatoxin B1 (AFB1). Milk is a \\
& highly nutritious food and is a source of necessary macro- and micro- \\
& nutrients for the growth, development and maintenance of human health.
\end{tabular}

* Corresponding author: Masoumeh Mahmoodi Maymand MSc of Toxicology, Standard Research Institute (SRI), Karaj, Iran. E-mail: mah_maymand@standard.ac.ir

\section{Methods:}

The presence of AFM1 was investigated in 70 samples of imported pasteurized and powdered milk products available to the Iranian consumers. The level of AFM1 was determined by HPLC method equipped with immunoaffinity cleanup.

\section{Results:}

The results showed that $32 \%$ of the analyzed samples were positive for AFM1 at $0.05-3.31 \mu \mathrm{g} / \mathrm{kg}$. Also, $16 \%$ of analyzed samples were positive for AFM1at concentrations higher than the limit permitted by the Iranian standards.

\section{Conclusion:}

The detection of AFM1 contamination in the analyzed samples indicates the importance of the health of animal feeds. Thus, monitoring the imported feed materials, especially those arriving at Iranian borders is crucial in the prevention of AFM1 and AFB1 contaminations spreading across the domestic market.

Keywords:

Aflatoxins M1 and B1; HPLC; Immunoaffinity Cleanup; Pasteurized Liquid and Powdered Milk.

How to cite this paper

Mahmoodi Maymand M, Mazaheri M, Talebi Mehrdar M. Determination of Aflatoxin M1 in Pasteurized Liquid and Powdered Milk Products Imported to Iran. Iran J Toxicol. 2019; (2):19-23

\section{INTRODUCTION}

Mycotoxins are the secondary metabolites from molds and have adverse effects on humans, animals, and crops, resulting in illnesses and economic losses. They are structurally and functionally diverse group of organic compounds that affect humans and animals alike (1). Mold contaminations have challenged the safety, production and processing of feeds because of the undeniable role in the spoilage and toxicity consequences on the human health and economy ( $\underline{2})$. Aflatoxins are mycotoxins of major concern to dairy industry. AflatoxinM1 (AFM1) is a hepatocarcinogen found in the milk from animals that have consumed feeds contaminated with aflatoxin B1(AFB1). The latter is the main metabolite produced by the genus Aspergillus fungi, such as $A$. flavus, $A$. parasiticus and $A$. nomius ( $\underline{3})$. The toxin can also be found in milk, dairy products, meat and eggs.

Milk is a highly nutritious food and is a source of essential macro- and micro-nutrients for the growth, development and maintenance of human health. However, it may also be the source of natural food contaminants that cause diseases. The presence of aflatoxin M1 (AFM1) in milk and dairy products throughout the world has been known over the past three decades. Milk and dairy products contamination with aflatoxin $\mathrm{M} 1$ has been a major problem worldwide, especially in the developing countries over the past ten to twenty years (ㅍ). Aflatoxin M1 is 
associated with carcinogenicity, genotoxicity, mutagenicity, and teratogenicity, representing a human health concern worldwide (므). In the assessment of cancer risks, infants are more exposed to toxic contaminants in milk than adults because it is a major constituent of their diet. Therefore, the presence of AFM1 in milk and dairy products is a major risk to humans (ㅁ) . AFM1 can be found in dairy products because it is resistant to heat during processing ( $\underline{7})$. AFM1 is quite stable during normal milk processing, such as pasteurization, and if present in raw milk, it may survive and appear in the final products available for human consumption. AFM1 can cause acute and chronic mycotoxicosis mainly through the ingestion of contaminated milk (ㅁ) . Most government oversight agencies worldwide have established regulations for the allowable limits of aflatoxins in human and animal food products. The limits for AFM1in milk and dairy products have also been established in various countries. The commercially produced powdered milk is used in variety of food products, such as ice cream, cakes, snacks and cereal products. Iranian National Standardization Organization (INSO) has set the legal limits for AFM1 at $1 \mu \mathrm{g} / \mathrm{mL}$ in commercially produced powdered milk (ISIRI 5925, 2002). This is also a mandatory limit for all imported powdered milk and dairy products.

Due to the importance of the topic and lack of recent scientific investigations in Iran, this study investigated the incidence of AFM1 in imported powdered milk samples collected at several Iranian ports.

\section{MATERIALS AND METHODS}

Chemicals: Standards of AFM1 were supplied from Sigma Chemical Company (St. Louis, USA) and the AFM1 immunoaffinity columns were obtained from VICAM Company (USA). The analytical grade solvents (methanol and acetonitrile) were purchased from MERCK (Germany) and stock standard of AFM1 was obtained from Sigma. The distilled and deionized water was prepared by Millipore purification system (USA). Concentration of stock standard solution of AFM1 was $100 \mu \mathrm{g} / \mathrm{mL}$ which was prepared in acetonitrile and wrapped in aluminum foil at $-20^{\circ} \mathrm{C}$. Five working solutions were prepared from the stock standard solution in the same solvent and stored in glassstoppered tubes at $0^{\circ} \mathrm{C}$. HPLC was used for the determination of AFM1. Waters HPLC equipped with quaternary pump, fluorescence detector and auto injector used with a stainless steel reverse phase column (Athena C18-wp, 100A, $4.6 \mathrm{~mm} \times 250 \mathrm{~mm}$, $5 \mu \mathrm{m})$.

Sampling and Sample Preparation: Commercially available imported powdered milk samples were collected between 2014 and 2017 according to Commission Regulation (EC) No. 401/2006, "Laying Down the Methods of Sampling and Analysis for the Official Control of the levels of Mycotoxins in Food Stuffs". Pasteurized milk samples were collected from
Tehran market randomly. Samples were received from the mycotoxins laboratory at the Standard Research Institute of Iran in Karaj, Iran. Sample analysis was performed by HPLC method according to the Iranian National Standard 7133 (Milk and dairy products determination of AFM1 by HPLC method immunoaffinity column clean up- test method). Three processing steps were performed for each sample: a) extraction of AFM1, b) cleaning up or purification, and c) chromatographic analysis. The description of each step is as follows:

Extraction: Powdered milk samples (10g) were dissolved in $100 \mathrm{~mL}$ water at $30-40^{\circ} \mathrm{C}$ and mixed thoroughly. Sixty $\mathrm{ml}$ of this solution was centrifuged and the fat phase was removed. The same process was followed for the pasteurized milk samples.

Cleanup: Aflatest immunoaffinity column (VICAM, USA) was used for the cleaning of the samples. First, 10 $\mathrm{ml}$ phosphate buffer saline (PBS) was passed through each immunoassay column and $20 \mathrm{ml}$ of the filtrate was passed through at a flow rate of $1 \mathrm{drop} / \mathrm{sec}$. The column was then washed with $10 \mathrm{ml}$ water, twice and was dried using a vacuum pump. Then, 2500ml acetonitrile (HPLC grade) was passed through the column, was collected in a dark vial, and was dried at 40-50ㄷ․ One $\mathrm{ml}$ of the mobile phase was added to the vial and mixed thoroughly.

Sample Analysis: The chromatographic analysis was performed on an HPLC column. One hundred microliter of the samples were injected into the HPLC column and heated to $40^{\circ} \mathrm{C}$. The combination of mobile phase for the fluorescent detection of AFM1 was: $1400 \mathrm{ml}$ water + $440 \mathrm{ml}$ acetonitrile $+160 \mathrm{ml}$ methanol $(1 \mathrm{ml} / \mathrm{min})$. The excitation and emission wavelengths were $360 \mathrm{~nm}$ and $440 \mathrm{~nm}$, respectively. The recovery of analysis was calculated in each working day and samples were fortified with aflatoxin M1. Sample fortification was done at maximum permitted limit in powdered milk according to Iranian National Standard (ISIRI No. 5925) and the process was completed, using fortified samples. For the quantification of AFM1 in samples, a calibration curve with five points was drawn in each working day and the linearity of curves was checked. The limit of quantification (LOQ) was $0.5 \mu \mathrm{g} / \mathrm{kg}$. The recoveries were generally $80-100 \%$.

\section{RESULTS}

Figure 1 shows the concentration of AFM1 in analyzed samples. The amount of AFM1in liquid and powdered milk are shown in Figures 2-6. Twenty milk samples (10 liquid \& 10 powdered), i.e., $32 \%$ of analyzed samples, were positive for AFM1at contamination levels of 0.05 to $3.31 \mu \mathrm{g} / \mathrm{kg}$. Sixteen percent of the analyzed milk samples (8 liquid \& 2 powdered) showed AFM1concentrations higher than the limit established by the Iranian standard regulations: liquid milk: $0.1 \mu \mathrm{g} / \mathrm{kg}$; powdered milk: $1 \mu \mathrm{g} / \mathrm{kg}$. The mean concentration of aflatoxin M1 for the samples was $0.18 \mu \mathrm{g} / \mathrm{kg}$. 


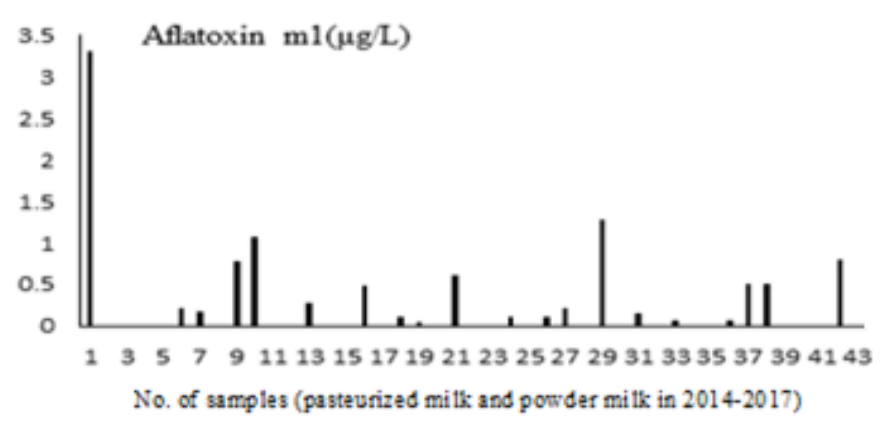

Figure 1. Concentration of aflatoxin M1 in pasteurized liquid and powder milk samples (2014-2017).

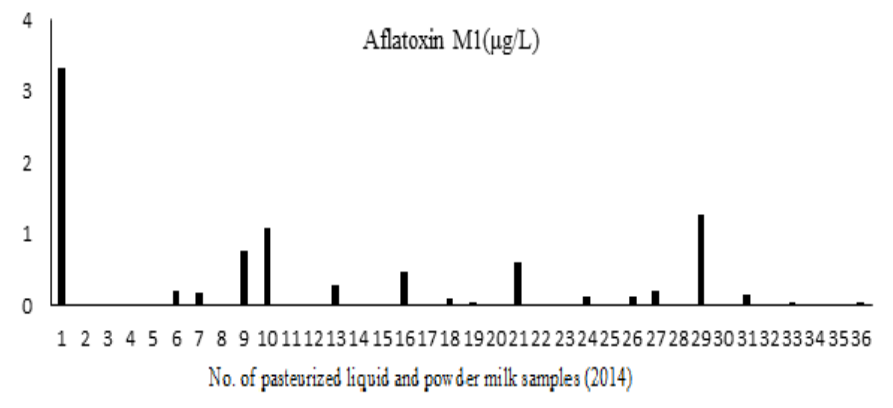

Figure 2. Concentration of aflatoxin M1 in pasteurized liquid and powder milk samples (2014).

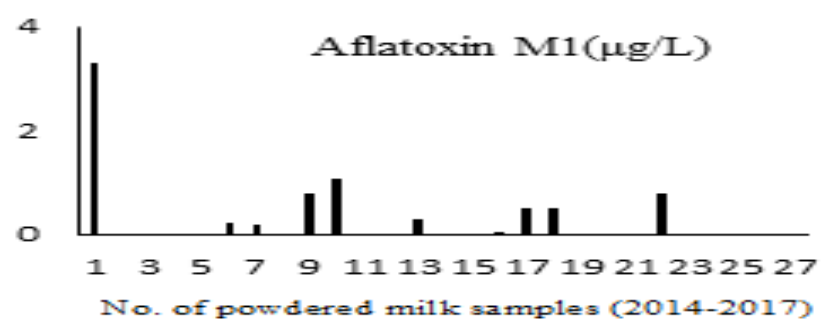

Figure 3. Concentration of aflatoxin M1 in powder milk samples (2014-2017).

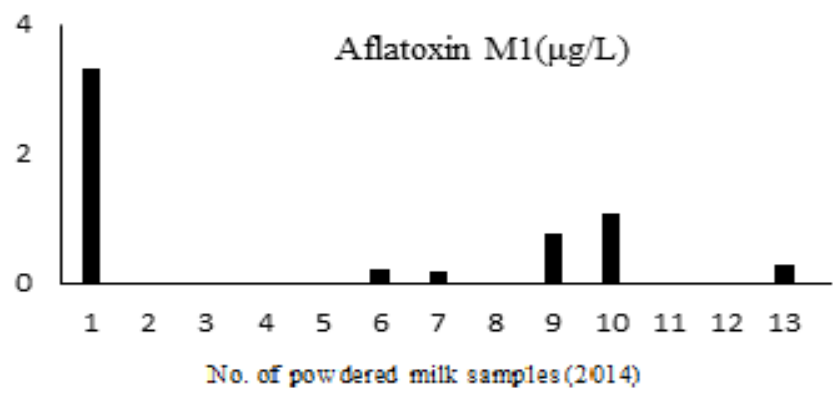

Figure 4. Concentration of aflatoxinM1 in powder milk samples (2014).

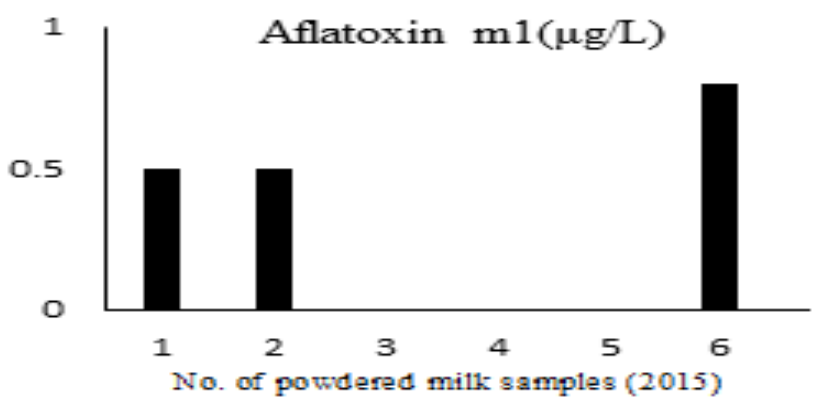

Figure 5. Concentration of aflatoxin M1 in powder milk samples (2015).

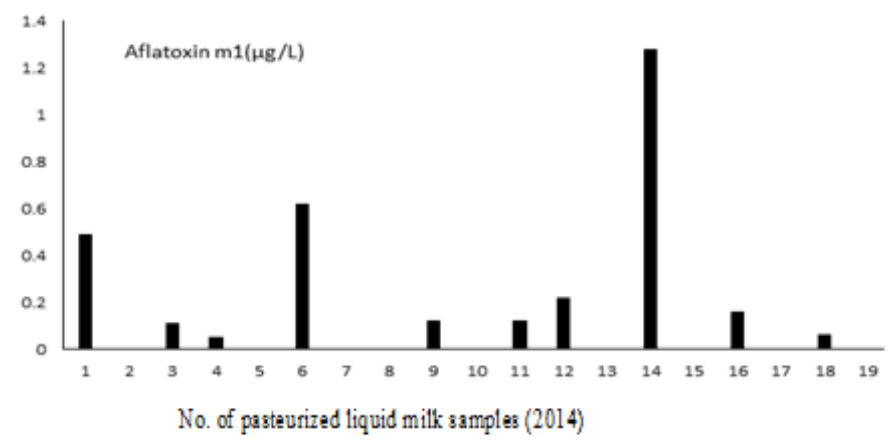

Figure 6. Concentration of aflatoxin M1 in pasteurized milk samples (2014).

\section{DISCUSSION}

Aflatoxin M1 is a 4-hydroxy derivative of AFB1, which can be found in milk products obtained from livestock that ingested feeds contaminated with AFB1( $\underline{4})$. Aflatoxin M1is a hepatocarcinogenic derivative of aflatoxin B1 excreted into the milk after ingestion of feeds contaminated with certain mold species. Because of the important role of dairy products especially milk in human diet, there is a great concern about the presence of AFM1 in milk and other dairy products ()). AFM1 exhibits lower toxicity than AFB1. This toxin has been classified by the International Agency for Research on Cancer (IARC) (10). Also, it has mutagenic effects and poses health concerns to humans (11). Powdered Milk is a popular dairy type in human daily diet, thus its quality and safety directly impacts the health of consumers. Evidently, milk has the greatest potential for introducing AFM1 into human diet (12). In order to protect the public, several countries and international organizations have established regulations for the maximum allowable level of AFM1 in milk and dairy products. The European Commission regulations has set the maximum residual levels for AFM1 in milk at $0.05 \mu \mathrm{g} / \mathrm{kg}(\underline{13})$. Accordingly, the maximum permitted limit for liquid milk AFM1 is $0.01 \mu \mathrm{g} / \mathrm{kg}$ while the limit for the commercially powdered milk is $1 \mu \mathrm{g} / \mathrm{kg}$ by the Iranian standards (14).

Wijaya et al (7) detected AFM1 in powdered and sweetened condensed milk available in several cities in Java. The study reported that the concentration of AFM1 in powdered milk ranged from undetectable to $0.549 \mu \mathrm{g} / \mathrm{kg}$, with $55 \%$ of the contaminations ranged between lest than 0.05 to $0.2 \mu \mathrm{g} / \mathrm{kg}$. On the other hand, the AFM1 levels in sweetened condensed milk ranged from undetectable to $0.056 \mu \mathrm{g} / \mathrm{kg}$, with $43.7 \%$ of the contaminations ranged between 0.025 and $0.05 \mu \mathrm{g} / \mathrm{kg}$. All of the powdered and sweetened condensed milk samples met the maximum allowable level of AFM1, according to Indonesian standards (프). Nor Shifa Shuib et al. determined the AFM1 concentration in milk and dairy products using HPLC fluorescence with postcolumn photochemical derivatization. They demonstrated that only $10 \%$ of their samples were contaminated with AFM1. The contamination level was below the Malaysian and European regulation limits (15). Maria Helena Iha et al. (트) investigated the incidence and occurrence of AFM1 in Brazilian milk and infant formulas, using immunoaffinity column 
purification, liquid chromatography separation and fluorescence detection. According to this study, AFM1 was detected in $83 \%$ of the milk samples $(>3 \mathrm{ng} / \mathrm{kg})$ with the concentration ranging from 8 to $437 \mathrm{ng} / \mathrm{kg}$ for liquid milk, and 20-760ng/kg for powdered milk, and AFM1 was not found in the infant formulas.

Another study conducted in Bangkok (17) determined the occurrence of AFM1 in 79 commercially powdered milk samples between 2010 and 2014. In this study, $15 \%$ of the samples were contaminated with AFM1 at 0.005-0.135 ng/mL in reconstituted powdered milk. The data indicated that the risk of AFM1 was safely low in commercially powdered milk in Bangkok, Thailand, (17). Sartori et al. (2015) examined 70 powdered milk samples and determined the concentration of AFM1and M2. AFM1 was found in $74 \%$ of the powdered milk samples at concentrations ranging from 0.08 to $1.19 \mu \mathrm{g} / \mathrm{kg}$. However, the AFM1 concentrations in milk samples were lower than the maximum permitted level

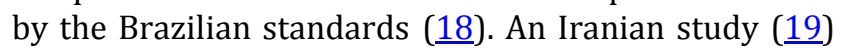
evaluated the AFM1 contamination in milk samples in Mashhad and found that $100 \%$ of the tested samples had AFM1 at $16.16 \mathrm{ng} / \mathrm{L}$ on average (range; 2-64ng/L). However, the AFM1 concentration in all samples fell below the Iranian National Standard for the toxin (19).

In a Chinese study in 2012, 31 liquid and powdered milk samples were analyzed and the AFM1 contamination was found only in 8 samples which did not exceed the Chinese legal limit of $0.5 \mu \mathrm{g} / \mathrm{kg}(\underline{20})$. In another Iranian study, AFM1 was detected by ELISA method in all of the 42 powdered milk samples at varying levels depending on the season. In the Spring, Fall and Winter, the range of AFM1 levels in the analyzed samples were 51-914, 32-640 and 32-879 $\mathrm{ng} / \mathrm{kg}$, respectively, with the means for the season were 305,278 and $285 \mathrm{ng} / \mathrm{kg}$, respectively (21).

A Syrian study in 2009 assessed the incidence of AFM1 in raw, pasteurized and powdered milk. The results of this study indicated that $80 \%$ of tested samples were contaminated with AFM1 at varying levels, ranging from 20 to $765 \mathrm{ng} / \mathrm{L}$. In this study, the percentage of the samples contaminated with AFM1 exceeded the American, Syrian and European allowable limits of $22 \%, 38 \%$ and $52 \%$, respectively (22). There are some studies on the AFM1 incidence of milk in Iran. In 2010, the occurrence and concentration range of AFM1 were investigated by ELISA method in 210 milk samples from Tehran supermarkets and reported that $55.2 \%$ of the samples were contaminated (23). Also, pasteurized milk samples $(\mathrm{N}=91)$ collected from popular markets in four large Iranian cities were examined for AFM1 by thin layer chromatography method. In this study, the toxin was detected in $72.5 \%$ of the samples $(\mathrm{N}=66)$, with the mean concentrationof $0.052 \mu \mathrm{g} / \mathrm{L}$ (range: 0.013-0.250 $\mu \mathrm{g} / \mathrm{L})(\underline{24})$. In a more recent study, 240 samples of powdered milk were collected from ten Tehran dairy plants and were analyzed for the presence of AFM1, using ELISA method. AFM1 was found in $64.6 \%$ of the samples $(\mathrm{N}=155)$ with an average concentration of $29.85 \pm 19 \mathrm{ng} / \mathrm{L}(\underline{25})$.

\section{CONLUSION}

The presence of AFM1 contamination in milk and various dairy products from the Iranian and international markets emphasizes the importance of the health of animal feeds. In this context, monitoring animal feeds for AFB1 and imported dairy products at the national borders are among the crucial steps in preventing AFM1 contamination from entering the national markets and people's diets. Also, the conditions of storage and transportation of animal feeds should be monitored regularly to avoid AFB1contaminations entering animal feeds. This contaminant leads to the development of AFM1in milk and dairy products, and places the health of people, especially children and older adults at great risks.

\section{ACKNOWLEDGMENTS}

The authors gratefully acknowledge the support of Biology Department, Standard Research Institute, Karaj, Iran. We also thank our colleague, Mr. Kazemi, for his collaboration with performing the laboratory experiments. Authors testify that this material has not been published in whole or in part elsewhere and the manuscript is not currently under consideration by another peer-reviewed journal.

\section{CONFLICT OF INTEREST}

The authors declare that there was no conflict of interest with any entity in conducting this research.

\section{REFERENCES}

1. Haschek WM, Rousseaux CG, Wallig MA. In: Haschek and Rousseaux's Handbook of Toxicologic Pathology. $3^{\text {rd }}$ Ed. Editors: Haschek et al. Elsevier/Academic Press, Vol. 1. Amsterdam, Netherlands. ISBN: 9780124157637. 2013

2. Campagnollo FB, Ganev KC, Khaneghah AM, Portela JB, Cruz AG, Granato D, et al. The occurrence and effect of unit operations for dairy products processing on the fate of aflatoxin M1: A review. Food Control. 2016;68:310329.

3. Tajkarimi M, Aliabadi-Sh F, Salah Nejad A, Poursoltani H, Motallebi AA, Mahdavi H. Aflatoxin M1 contamination in winter and summer milk in 14 states in Iran. Food Control. 2008;19(11):1033-1036.

4. Iqbal SZ, Jinap S, Pirouz AA, Ahmad Faizal AR. Aflatoxin M1 in milk and dairy products, occurrence and recent challenges: A review. Trends in Food Science \& Technology. 2015;46(1):110-119.

5. Womack ED, Sparks D, Brown AE. Aflatoxin M1 in milk and milk products: A short review. World Mycotoxin Journal. 2016;9(2):305-315.

6. Khlangwiset P, Shephard GS, Wu F. Aflatoxins and growth impairment: a review. Critical Reviews in Toxicology. 2011;41(9):740-755.

7. Wijaya H, I Wardayanie N, Widjajanti R, F Silitonga R. Detection of aflatoxin M1 in powdered milk and sweetened condensed milk products in several cities in Java with HPLC-fluorescence method. IOP Conference Series: Earth and Environmental Science: IOP Publishing; conference 1, 2018. 
8. Naeimipour F, Aghajani J, Kojuri S, Ayoubi S. Useful approaches for reducing aflatoxin M1 content in milk and dairy products. Biomedical and Biotechnology Research Journal. 2018;2(2):94-99.

9. Duarte SC, Almeida AM, Teixeira AS, Pereira AL, Falcão AC, Pena A, et al. Aflatoxin M1 in marketed milk in Portugal: Assessment of human and animal exposure. Food Control. 2013;30(2):411-417.

10. Bakirci I. A study on the occurrence of aflatoxin M1 in milk and milk products produced in Van province of Turkey. Food Control. 2001;12(1):47-51.

11. Sassahara M, Netto D, K Yanaka E. Aflatoxin occurrence in foodstuff supplied to dairy cattle and aflatoxin M-1 in raw milk in the North of Parana state. Food and Chemical Toxicology. 2005;43(6):981-984.

12. Roussi V, Govaris A, Varagouli A, Botsoglou NA. Occurrence of aflatoxin M1 in raw and market milk commercialized in Greece. Food Additives and Contaminants. 2002;19(9):863-868.

13. Commission E. Setting maximum levels of certain contaminants in foodstuffs. Commission regulation No 1881/2006, December 19th: Official Journal of European Union. 2006;1:11.

14. Iran IoSaIRo. Food and feed mycotoxins-maximum tolerated level. Tehran, Iran.: Institute of Standard and Industrial Research of Iran; 2019;1:8.

15. Shuib NS, Makahleh A, Salhimi SM, Saad B. Determination of aflatoxin M1 in milk and dairy products using high performance liquid chromatography-fluorescence with post column photochemical derivatization. Journal of Chromatography A. 2017;1510:51-56.

16. Iha MH, Barbosa CB, Okada IA, Trucksess MW. Aflatoxin M1 in milk and distribution and stability of aflatoxin M1 during production and storage of yoghurt and cheese. Food Control. 2013;29(1):1-6.
17. Soontornjanagit M, Kawamura O. Occurrence of aflatoxin M1. In commercial powdered milk in Bangkok, Thailand. Mycotoxins. 2015;65:75-79.

18. Victor Sartori A, Swensson de Mattos J, Heloísa Paulino de Moraes M, Wanderley da Nóbrega A. Determination of Aflatoxins M1, M2, B1, B2, G1, and G2 and Ochratoxin A in UHT and Powdered Milk by Modified QuEChERS Method and Ultra-High-Performance Liquid Chromatography Tandem Mass Spectrometry. Food Analytical Methods. 2015;8:2321-2330.

19. Sani AM, Nikpooyan H. Determination of aflatoxin M1 in milk by high-performance liquid chromatography in Mashhad (north east of Iran). Toxicology and Industrial Health. 2013;29(4):334-338.

20. Wang Y, Xuebo L, Xiao C, Wang Z, Wang J, Xiao H, et al. HPLC determination of aflatoxin M1 in liquid milk and milk powder using solid phase extraction on OASIS HLB. Food Control. 2012;28:131-134.

21. Kamkar A. Detection of aflatoxin M1 in powdered milk samples by ELISA. J Vet Res. 2007;63:80-84.

22. Ghanem I, Orfi M. Aflatoxin M1 in raw, pasteurized and powdered milk available in the Syrian market. Food Control. 2009;20(6):603-605.

23. Heshmati A, Milani JM. Contamination of UHT milk by aflatoxin M1 in Iran. Food Control. 2010;21(1):19-22.

24. Fallah A. Aflatoxin M1 contamination in dairy products marketed in Iran during winter and summer. Food Control. 2010;21(11):1478-1481.

25. Noori N, Karim G, Raeesian M, Khaneghahi Abyaneh H, Bahonar A, Akhondzadeh Basti A, et al. Antibiotic residues and aflatoxin M1 contamination in milk powder used in Tehran dairy factories, Iran. Iranian Journal of Veterinary Medicine. 2013;7(3):221-226. 